\title{
Effects of Bamboo Species, Steam-heating Treatment, and Adhesives on Mechanical Properties and Dimensional Stability of Oriented Bamboo Scrimber Boards
}

\author{
Chia-Ju Lee and Min-Jay Chung * \\ Effects of bamboo species, adhesives, and steam-heating treatment \\ (SHT) were examined relative to mechanical properties and dimensional \\ stability of oriented bamboo scrimber board (OBSB) made from makino \\ bamboo (Phyllostachys makinoi Hayata) and moso bamboo ( $P$. \\ pubescens (Mazel)) strips. Results indicated that OBSB produced using \\ makino bamboo culms bonded with water-soluble phenol formaldehyde \\ resin (PF) had significantly higher ultrasonic wave velocity $\left(V_{u}(/ /)\right)$, tap tone \\ sound velocity $\left(V_{t}(/ /)\right)$, dynamic modulus of elasticity $\left(\mathrm{DMOE}_{\mathrm{u}}(/ /)\right)$, and \\ $\mathrm{DMOE}_{\mathrm{t}}(/ /)$ than that produced using moso bamboo bonded with water- \\ soluble urea formaldehyde resin (UF) $(p<0.05)$. The two types of OBSB \\ showed the same trend of $\mathrm{DMOE}_{\mathrm{u}}>\mathrm{DMOE}_{\mathrm{t}}>$ modulus of elasticity (MOE). \\ In addition, OBSB made using steam-heated makino bamboo and PF had \\ the largest modulus of rupture (MOR) (210.5 MPa), exceeding that of \\ OBSB made using laminated bamboo timber and wood-plastic composite \\ (WPC). However, OBSB made using steam-heated moso bamboo and UF \\ exhibited the highest screw holding strength (SHS). Improvement in \\ dimensional stability was observed in OBSB manufactured using steam- \\ heated culms. Finally, OBSB glued with UF had lower water absorption, \\ thickness swelling, and volumetric swelling than that glued with PF.
}

Keywords: Bamboo culms; Phenol formaldehyde resin; Urea formaldehyde resin; Oriented bamboo scrimber board; Mechanical property; Dimensional stability

Contact information: Experimental Forest, National Taiwan University, No. 12, Section 1, Chien-Shan Road, Chu-Shan, Nantou Hsien, 55750, Taiwan; *Corresponding author: r90625001@ntu.edu.tw

\section{INTRODUCTION}

Bamboo has high carbon fixation efficiency, a short renewal cycle, and good mechanical strength properties. In the past two decades, many countries have developed methods for applying bamboo as structural materials in engineering and construction (Obata et al. 2006; Abdul Khalil et al. 2012; Sharma et al. 2015a). However, owing to increasing demand for diverse applications of bamboo, problems with mass production of bamboo materials have arisen. Laminated bamboo and bamboo particleboards have been widely used in furniture making, flooring, and interior decoration (Lee et al. 1998; Nugroho and Ando 2001; Obata et al. 2001; Lee and Liu 2003; Okubo et al. 2004; Sulastiningsih and Nurwati 2009; Verma and Chariar 2012; Lee et al. 2012). However, their processing causes defects in strength properties and incurs high costs, thus limiting their utilization. In view of these disadvantages, bamboo research scholars developed oriented bamboo scrimber board (OBSB), which has an ideal surface texture, high hardness, and good longitudinal compressive strength (Wang 1989; Yu and Yu 2013; Yu et al. 2015; Sharma 
et al. 2015a,b), suited for indoor and outdoor flooring, railings, furniture making, and structural engineering.

At present, only Chung and Wang (2017) have evaluated the strength properties of different OBSBs made of moso bamboo (Phyllostachys pubescens) from China and Taiwan. Their results showed that OBSB made using moso bamboo from Taiwan at a density of $1.0 \mathrm{~g} / \mathrm{cm}^{3}$ had higher modulus of elasticity (MOE), modulus of rupture (MOR), and internal bonding strength (IB) than OBSB made using moso bamboo from China. Chung and Wang (2018) also evaluated the effects of epidermis-peeling treatment (EPT) and steam-heating treatment (SHT) on OBSB made from makino ( $P$. makinoi) and moso bamboo. Their findings revealed that OBSB made from regular makino bamboo and moso bamboo originating from Taiwan had higher MOE, MOR, and screw holding strength (SHS), indicating higher mechanical strength. In the production of wood composites, adhesives are required for bonding. Past studies have reported variations in strength, dimensional stability, and durability of wood composites due to differences in gluing properties of the adhesives used (Liu 1984; Pizzi 1993; Uysal 2005; Bal and Bektaş 2012). Therefore, choosing the appropriate adhesive is important when developing wood composites. Phenol formaldehyde resin (PF) and urea formaldehyde resin (UF) are the two most widely used adhesives for producing furniture and wood composites (Liu et al. 1993). Prior to this study, there has been no research on effects of PF and UF used as adhesives on the physical strength, mechanical strength, and dimensional stability of OBSB.

In this study, OBSBs of $1.0 \mathrm{~g} / \mathrm{cm}^{3}$ density were made using treated and non-heattreated moso bamboo and makino bamboo culms from Taiwan and glued with PF and UF. Their mechanical properties and dimensional stability were evaluated using nondestructive testing. Findings from this study will provide the bamboo processing industry a better understanding of the appropriate bamboo species, pre-treatment, and adhesives for making engineered wood with good mechanical properties and dimensional stability.

\section{EXPERIMENTAL}

\section{Materials}

Three-year-old moso bamboo (Phyllostachys pubescens (Mazel)) and makino bamboo (Phyllostachys makinoi Hayata) culms were collected from the Experimental Forest of National Taiwan University in Shuili Township, Nantou County, Taiwan, in October 2015. Figure 1 illustrates the manufacturing of OBSB specimens. First, all bamboo culms were cut into 2-cm-wide strips and then pre-treated with an alkaline solution containing $2 \%$ potassium hydroxide $(\mathrm{KOH})$ at $100{ }^{\circ} \mathrm{C}$ for $30 \mathrm{~min}$. The strips were then oven-dried at $80^{\circ} \mathrm{C}$. For SHT, bamboo strips were placed in a steam-heating furnace at 120 ${ }^{\circ} \mathrm{C}$ for $6 \mathrm{~h}$, followed by air-drying. The 2 -cm-wide strips were further extruded into thin strips of $450 \mathrm{~mm} \times 1.0$ to $2.0 \mathrm{~mm}$ (length $\times$ width) by mechanical processing. The thin strips were dried at $80{ }^{\circ} \mathrm{C}$ for $12 \mathrm{~h}$ to reach a constant weight (moisture content of about $8 \%$ ) and then placed unidirectionally in an iron frame of $450 \mathrm{~mm} \times 450 \mathrm{~mm} \times 12 \mathrm{~mm}$ (length $\times$ width $\times$ thickness).

Board density of $1.0 \mathrm{~g} / \mathrm{cm}^{3}$ and bonding agent at $10 \mathrm{wt} \%$ of raw material were adopted according to the Chinese National Standards (CNS) 2215 specifications for weight of bamboo strips and quantity of adhesive used, respectively for the test on particleboards. Two adhesives were used in this study: water-based UF with a solids content of $63.6 \%$ and 
alcohol-based PF with a solids content of $58.1 \%$ (Wood Glue Industrial Co., Ltd., Tainan, Taiwan). The strips were hot-pressed (STH No. 4; China Hydraulic Industry Co., Ltd., Taipei County, Taiwan) at curing temperatures of $120^{\circ} \mathrm{C}$ and $145^{\circ} \mathrm{C}$ at $150 \mathrm{kgf} / \mathrm{cm}^{2}$ for 12 min followed by 10 -min cooling. Prior to the experiments, all specimens were conditioned in a controlled environment at $20{ }^{\circ} \mathrm{C}$ and a relative humidity (RH) of $65 \%$ for 2 weeks. Table 1 summarizes the treatment conditions and codes for the eight experimental OBSB groups $(\mathrm{n}=9)$.

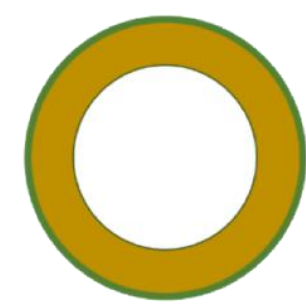

Bamboo culms

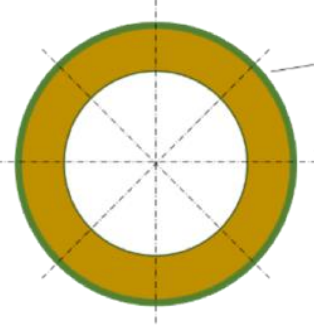

Chipping

Gluing and thermo-compression

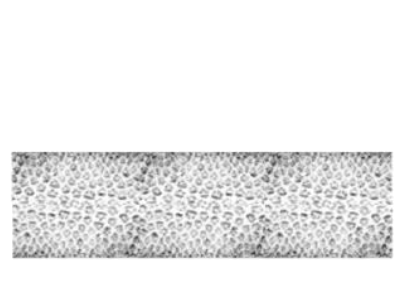

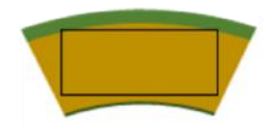

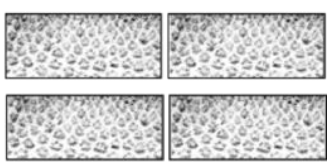

Peeling

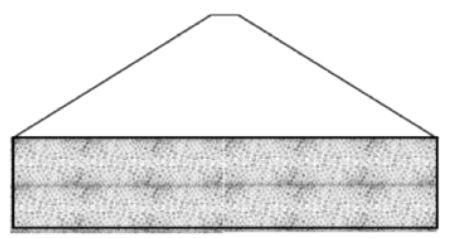

Oriented bamboo scrimber board $\diamond$

Fig. 1. Manufacturing process of OBSB

Table 1. Experimental OBSB Groups and their Codes

\begin{tabular}{|c|c|c|c|c|}
\hline No. & Species & Heat Treatment & Adhesives & Code \\
\hline 1 & \multirow{4}{*}{ Makino bamboo } & \multirow[b]{2}{*}{ Yes } & UF & $\mathrm{Pm}-\mathrm{H}-\mathrm{U}$ \\
\hline 2 & & & PF & $\mathrm{Pm}-\mathrm{H}-\mathrm{P}$ \\
\hline 3 & & \multirow[b]{2}{*}{ No } & UF & $\mathrm{Pm}-\mathrm{U}$ \\
\hline 4 & & & PF & $\mathrm{Pm}-\mathrm{P}$ \\
\hline 5 & \multirow{4}{*}{ Moso bamboo } & \multirow{2}{*}{ Yes } & UF & Moso-H-U \\
\hline 6 & & & PF & Moso-H-P \\
\hline 7 & & \multirow[b]{2}{*}{ No } & UF & Moso-U \\
\hline 8 & & & PF & Moso-P \\
\hline
\end{tabular}

\section{Methods}

Density

According to CNS 451 (2013), after the OBSB specimens were conditioned at 20 ${ }^{\circ} \mathrm{C}$ and $\mathrm{RH}$ of $65 \%$ for 4 weeks, the dry weight and volume were measured, and the density was calculated. 


\section{Moisture content}

According to CNS 452 (2005), OBSB cubes of $3 \mathrm{~cm}^{3}$ in size were oven-dried at $100{ }^{\circ} \mathrm{C}$ to $105^{\circ} \mathrm{C}$ to constant weight. The difference in weight before and after drying indicates the moisture content $(\mathrm{MC} \%)$ in the specimens.

\section{Non-destructive evaluation}

Non-destructive testing (NDT) was conducted to evaluate the ultrasonic-wave velocity $\left(V_{\mathrm{u}}\right)$ and dynamic modulus of elasticity $\left(\mathrm{DMOE}_{\mathrm{u}}\right)$ using an ultrasonic analyzer (Sylvatest Duo; CBS \& CBT, Saint-Sulpice, Switzerland) at a frequency of $22 \mathrm{kHz}$. The OBSB specimens of size $240 \mathrm{~mm} \times 50 \mathrm{~mm} \times 12 \mathrm{~mm}$ (length $\times$ width $\times$ thickness) were placed between the transmitting and receiving transducers, and the transmission time of the ultrasonic wave (travel time) was recorded.

Another NDT was performed to evaluate the tap tone sound velocity $\left(V_{\mathrm{t}}\right)$ and dynamic modulus of elasticity $\left(\mathrm{DMOE}_{\mathrm{t}}\right)$ using a tap tone NDT device (Multi-purpose FFT analyzer CF-5220; Ono Sokki Co., Ltd., Yokohama, Japan). Each OBSB specimen of size $240 \mathrm{~mm} \times 50 \mathrm{~mm} \times 12 \mathrm{~mm}$ (length $\times$ width $\times$ thickness) was supported at the center by a piece of foam and struck on one end with a hard-rubber hammer. The tap tone was transmitted from the end hit with the hammer and received by the microphone placed at the other end. The instantaneously generated sound waveform was decomposed into a spectrum using the Fast Fourier Transform (FFT) (CF- 360Z; Ono Sokki Co., Yokohama, Japan) to measure the natural vibration frequency.

\section{Mechanical strength analysis}

The mechanical strength of OBSB specimens was examined according to the ASTM D1037 (2006) standard. The static bending test was performed using a universaltype testing machine (UH-10A; Shimadzu, Tokyo, Japan) according to the center-loading method for specimens. A concentrated bending load was applied at the center with a span 15 times the thickness of the specimen. Both MOE and MOR were calculated from the load-deflection curves.

\section{Nail withdrawal resistance analysis}

According to CNS 2215 (2012), OBSB specimens were placed in a controlled environment with $\mathrm{RH}$ of $65 \%$ for 3 weeks. The dimensions of each OBSB specimen were $100 \mathrm{~mm} \times 50.0 \mathrm{~mm} \times 12.0 \mathrm{~mm}$ (length $\times$ width $\times$ thickness), and those of the wood screws were $2.7 \mathrm{~mm} \times 16.0 \mathrm{~mm}$ (diameter $\times$ length). Wood screws were drilled vertically into OBSB specimens to a depth of $11.0 \mathrm{~mm}$ and then pulled up vertically at a rate of 2.0 $\mathrm{mm} / \mathrm{min}$. The maximum pull loading was measured, and the average of three measurements was recorded as the nail withdrawal resistance.

\section{Dimensional stability}

According to ASTM D1037 (2006), all OBSB specimens were placed parallel to each other at a depth of $30 \mathrm{~mm}$ under water and soaked for $2 \mathrm{~h}$ and $24 \mathrm{~h}$, and their weight, thickness, and volume before and after soaking were measured. Differences in weight, thickness, and volume before and after soaking were calculated to determine water absorption (WA\%), thickness swelling (TS\%), and volumetric swelling (S\%). 


\section{Statistical analysis}

The statistical software SPSS (IBM Corp., v.20, Armonk, NY, USA) was used as a data analysis tool in this study. All multiple comparisons of physical and mechanical properties were subjected to Tukey's tests and analysis of variance (ANOVA) tests. Significant differences between the mean values of the control and experimental specimens were determined using the Duncan's multiple range test.

\section{RESULTS AND DISCUSSION}

\section{Density and Moisture Content}

Both density and MC\% of wood and bamboo had significant effects on the strength, dimensional stability, and durability of composites made with these materials. Table 2 lists the density and MC\% of the eight experimental OBSB groups. Regardless of bamboo species and adhesive used, and whether steam-heated or not, the observed differences among the values of the density of all OBSB specimens before and after the 4-week conditioning ranged between 0.02 and $0.05 \mathrm{~g} / \mathrm{cm}^{3}$, indicating insignificant difference $(\mathrm{p}>$ 0.05). These results reveal that bamboo species, adhesive used, and heat treatment had no effect on OBSB density.

Table 2. Oven-dried Density and Moisture Content of Eight Experimental OBSB Groups

\begin{tabular}{|c|c|c|c|}
\hline \multirow{2}{*}{ Code } & \multicolumn{2}{|c|}{ Density $\left(\mathrm{g} / \mathrm{cm}^{3}\right)$} & $\mathrm{MC}(\%)$ \\
\cline { 2 - 4 } & $\mathrm{RH} 65 \%$ & Oven-dried & $\mathrm{RH} 65 \%$ \\
\hline $\mathrm{Pm}-\mathrm{H}-\mathrm{U}$ & $1.05(0.01)$ & $1.03(0.02)^{\mathrm{a}}$ & $7.47(0.26)^{\mathrm{a}}$ \\
\hline $\mathrm{Pm}-\mathrm{H}-\mathrm{P}$ & $1.04(0.03)$ & $1.03(0.04)^{\mathrm{a}}$ & $4.26(0.14)^{\mathrm{c}}$ \\
\hline $\mathrm{Pm}-\mathrm{U}$ & $0.99(0.01)$ & $0.97(0.02)^{\mathrm{a}}$ & $7.88(0.12)^{\mathrm{ab}}$ \\
\hline $\mathrm{Pm}-\mathrm{P}$ & $1.02(0.06)$ & $1.00(0.05)^{\mathrm{a}}$ & $5.23(0.43)^{\mathrm{bc}}$ \\
\hline Moso-H-U & $1.01(0.05)$ & $0.98(0.05)^{\mathrm{a}}$ & $7.20(0.13)^{\mathrm{ab}}$ \\
\hline Moso-H-P & $1.03(0.02)$ & $1.01(0.02)^{\mathrm{a}}$ & $4.70(0.23)^{\mathrm{bc}}$ \\
\hline Moso-U & $1.05(0.02)$ & $1.03(0.03)^{\mathrm{a}}$ & $6.74(0.20)^{\mathrm{b}}$ \\
\hline Moso-P & $1.03(0.02)$ & $1.02(0.02)^{\mathrm{a}}$ & $4.97(0.43)^{\mathrm{bc}}$ \\
\hline \multicolumn{4}{|r}{} \\
\hline \multicolumn{4}{|l}{} \\
\hline
\end{tabular}

However, variations in MC\% were observed in specimens made using different bamboo species and adhesives with and without heat treatment. As can be seen in Table 2, SHT reduced the MC\% of Pm-U and Pm-P from $7.88 \%$ and $5.23 \%$ to $7.47 \%$ and $4.26 \%$, respectively. In contrast, the changes in $\mathrm{MC} \%$ after SHT were inconsistent for Moso-OBSB glued with different adhesives. Though SHT decreased the MC\% of Moso-P from $4.97 \%$ to $4.70 \%$, it increased the MC\% of Moso-U from $6.74 \%$ to $7.20 \%$. A decrease in $\mathrm{MC} \%$ after SHT was also observed by Hakkou et al. (2005) when they assessed the effect of SHT on the wettability and mass loss of wood. The present findings also revealed lower MC\% in PF-glued OBSBs than in their UF-glued counterparts, which echo the results reported by Huang and Lin (1983). In their study on particleboards manufactured using UF, PF, and melamine formaldehyde resin (MF), water absorption and thickness of the board surface for different adhesives were in the order of MF < PF < UF. Good permeability and gluing 
properties between $\mathrm{PF}$ and makino bamboo contribute to low $\mathrm{MC} \%$, which indirectly improves dimensional stability.

\section{Ultrasonic-wave Velocity and Dynamic Modulus of Elasticity}

Table 3 shows the average $V_{\mathrm{u}}$ and $\mathrm{DMOE}_{\mathrm{u}}$ of the eight experimental OBSB groups. As shown, the $V_{\mathrm{u}(/ /)}$ of Pm-OBSB $(5020 \mathrm{~m} / \mathrm{s}$ to $5780 \mathrm{~m} / \mathrm{s})$ was slightly higher than that of Moso-OBSB (4917 m/s to $5071 \mathrm{~m} / \mathrm{s})$. With the exception of UF-glued Pm-OBSB, SHT decreased $V_{\mathrm{u}(/ /)}$, and Pm-OBSB specimens showed more significant reduction in $V_{\mathrm{u}(/ /)}$, indicating that SHT had a stronger effect on Pm than on Moso. Whether heat-treated or not, PF-glued OBSB specimens had higher $V_{\mathrm{u}(/ /)}$ than their UF-glued counterparts, but the differences were not statistically significant ( $\mathrm{p}>0.05)$.

The $\mathrm{DMOE}_{\mathrm{u}(/ /)}$ of Pm-OBSB (24.23 GPa to $34.39 \mathrm{GPa}$ ) was also slightly higher than that of Moso-OBSB (23.49 GPa to $24.81 \mathrm{GPa})$. However, contrasting trends were observed after SHT. For Pm-OBSB, SHT decreased the $\mathrm{DMOE}_{\mathrm{u}(/ /)}$ in PF-glued specimens but increased that in their UF-glued counterparts. For Moso-OBSB, SHT increased the $\mathrm{DMOE}_{\mathrm{u}(/ /)}$ in PF-glued specimens but decreased that in their UF-glued counterparts. Consequently, while Pm-P had greater $\mathrm{DMOE}_{\mathrm{u}(/ /)}$ than Pm-U, Pm-P had smaller $\mathrm{DMOE}_{\mathrm{u}}$ (I/) than Pm-U following SHT. A similar reversal was observed for Moso-OBSB. Initially Moso-U had greater $\mathrm{DMOE}_{\mathrm{u}(/ /)}$ than Moso-P; after SHT, Moso-U had smaller DMOE $\mathrm{D}_{\mathrm{u} / /)}$ than Moso-P. Changes in $\mathrm{DMOE}_{\mathrm{u}(/ /)}$ due to SHT, whether positive or negative, were larger in Pm-OBSB, again indicating that SHT had a more marked effect on Pm-OBSB than on Moso-OBSB (p < 0.05). Compared with the $V_{\mathrm{u}}(4016 \mathrm{~m} / \mathrm{s}$ to $4174 \mathrm{~m} / \mathrm{s})$ and $\mathrm{DMOE}_{\mathrm{u}}(10.4$ $\mathrm{GPa}$ to $11.4 \mathrm{GPa}$ ) obtained by Lee et al. (2012) for laminated board made with moso bamboo from China, higher $V_{\mathrm{u}}$ and $\mathrm{DMOE}_{\mathrm{u}}$ were observed for the OBSB specimens in this study. Such differences in $V_{\mathrm{u}}$ and $\mathrm{DMOE}_{\mathrm{u}}$ can be attributed to the higher board density of OBSB compared with bamboo laminated board. Hot pressing of bamboo after extrusion makes the bamboo structure denser. These results indicated the significant influence of density on $V_{\mathrm{u}}$ and $\mathrm{DMOE}_{\mathrm{u}}$.

\section{Tap Tone Sound Velocity and Dynamic Modulus of Elasticity}

Both tap tone sound velocity and $\mathrm{DMOE}_{\mathrm{t}}$ of the eight experimental OBSB groups showed slightly different trends compared with $V_{\mathrm{u}}$ and $\mathrm{DMOE}_{\mathrm{u}}$.

Table 3. $V_{\mathrm{u}(/ /)}, V_{\mathrm{t}(/)}, \mathrm{DMOE}_{\mathrm{t}(/ /)}$, and $\mathrm{DMOE}_{\mathrm{u}(/ /)}$ of Eight Experimental OBSB Groups

\begin{tabular}{|l|c|c|c|c|}
\hline Code & $V_{\mathrm{u}}(\mathrm{m} / \mathrm{s})$ & $V_{\mathrm{t}}(\mathrm{m} / \mathrm{s})$ & DMOE $_{\mathrm{u}}(\mathrm{GPa})$ & DMOE $_{\mathrm{t}}(\mathrm{GPa})$ \\
\hline $\mathrm{Pm}-\mathrm{H}-\mathrm{U}$ & $5780(57)^{\mathrm{b}}$ & $4547(51)$ & $34.39(0.62)^{\star *}$ & $19.48(0.94)$ \\
\hline $\mathrm{Pm}-\mathrm{H}-\mathrm{P}$ & $5071(53)^{\mathrm{b}}$ & $4605(58)$ & $24.23(0.97)^{\star *}$ & $19.99(0.80)$ \\
\hline $\mathrm{Pm}-\mathrm{U}$ & $5720(49)^{\mathrm{a}}$ & $5164(18)$ & $31.61(2.44)^{\star}$ & $25.76(1.80)$ \\
\hline $\mathrm{Pm}-\mathrm{P}$ & $5738(57)^{\mathrm{a}}$ & $5197(52)$ & $32.77(0.74)^{\star}$ & $27.48(0.86)$ \\
\hline Moso-H-U & $4917(50)^{\mathrm{b}}$ & $4523(56)$ & $23.49(0.99)^{\star *}$ & $20.66(0.94)$ \\
\hline Moso-H-P & $5030(52)^{\mathrm{b}}$ & $4629(42)$ & $24.81(0.53)^{\star *}$ & $21.54(0.74)$ \\
\hline Moso-U & $5050(57)^{\mathrm{b}}$ & $4547(51)$ & $24.23(0.97)^{\star *}$ & $19.99(0.80)$ \\
\hline Moso-P & $5071(53)^{\mathrm{b}}$ & $4605(58)$ & $23.89(0.62)^{\star *}$ & $19.48(0.94)$ \\
\hline
\end{tabular}

Results are mean \pm standard error (SE), $n=9$; numbers followed by different letters (a through e) are statistically different at the probability level of $p<0.05$ according to Tukey's test and ANOVA 
As shown in Table 3, the $V_{\mathrm{t}(/ /)}$ of Pm-OBSB $(4547 \mathrm{~m} / \mathrm{s}$ to $5197 \mathrm{~m} / \mathrm{s})$ was slightly higher than that of Moso-OBSB (4523 m/s to $4629 \mathrm{~m} / \mathrm{s})$. Except for PF-glued Moso-OBSB, SHT decreased $V_{\mathrm{t}(/ /)}$, and Pm-OBSB showed a more notable reduction, echoing the above finding that SHT had a stronger effect on Pm-OBSB than Moso-OBSB. In addition, whether heat-treated or not, PF-glued OBSB specimens had higher $V_{\mathrm{t}(/)}$ than their UFglued counterparts, but the differences were not statistically significant ( $p>0.05)$.

Similarly, the $\mathrm{DMOE}_{\mathrm{t}(/)}$ of Pm-OBSB (19.48 $\mathrm{GPa}$ to $\left.27.48 \mathrm{GPa}\right)$ was slightly higher than that of Moso-OBSB $(19.48 \mathrm{~m} / \mathrm{s}$ to $21.54 \mathrm{~m} / \mathrm{s})$. Regardless of the adhesive used, SHT decreased the $\mathrm{DMOE}_{\mathrm{t}(/)}$ of Pm-OBSB but increased the $\mathrm{DMOE}_{\mathrm{t}(/ /)}$ of Moso-OBSB, revealing that SHT had different effects on the two bamboo species. In addition, the reduction in $\mathrm{DMOE}_{\mathrm{t}(/ /)}$ for Pm-OBSB was more notable than the increase in $\mathrm{DMOE}_{\mathrm{t}(/)}$ for Moso-OBSB, again indicating that SHT had a greater impact on Pm-OBSB. With the exception of non-heat-treated Moso-OBSB, all PF-glued specimens had higher $\mathrm{DMOE}_{\mathrm{t}(/ /)}$ than their UF-glued counterparts, but the differences were not statistically significant ( $\mathrm{p}>$ 0.05). In comparison, both $V_{\mathrm{u}}$ and $\mathrm{DMOE}_{\mathrm{u}}$ of all OBSB specimens were higher than their $V_{\mathrm{t}}$ and $\mathrm{DMOE}_{\mathrm{t}}$. This finding is consistent with the results obtained by Lee and Yang (2010) in their evaluation of China fir laminae using NDT. Wang et al. (2008) also reported DMOEu > DMOEt > MOE in their study on domestic Japanese cedar, Taiwan fir, Douglas fir, and South pine.

\section{Mechanical Strength}

Figure 2 shows the MOE and MOR of the eight experimental OBSB groups. The MOE values of heat-treated OBSB specimens were higher than that of their non-heat-treated counterparts. Whether heat-treated or not, Pm-OBSB had higher MOE than their Moso-OBSB counterparts; and PF-glued specimens, had higher MOE than their UF-glued counterparts, but the differences were not statistically significant. As pointed out by Halabe et al. (1997) and Tsai (1985), DMOE exceeding MOE may be due to the types of test used. To obtain MOE using a bending test, the specimens are placed under a constant load for a long duration, resulting in torsional deformation and increased deflection due to shear forces. In contrast, DMOE can be determined using NDT with no or only short-term impact on the specimen. The same trend was observed for the MOR of the experimental OBSB specimens. The MOR of heat-treated OBSB specimens were significantly higher than that of their non-heat-treated counterparts, regardless of bamboo species and adhesives used. Moreover, whether heat-treated or not, PF-glued specimens had higher MOR than their UF-glued counterparts.

In summary, better strength properties were observed for Pm-OBSB. The highest MOR of $210.50 \mathrm{MPa}$ obtained for Pm-H-P far exceeded the peak MOR of 95.6 MPa for laminated board made with China-origin moso bamboo (Lee et al. 2012) and $35 \mathrm{MPa}$ to 45 MPa for polyethylene-wood composites (Geng and Simonsen 2004). Moreover, both SHT and PF contributed to enhanced strength in OBSBs. This finding is consistent with the results obtained by Çolak et al. (2004) that pine laminated wood laminates (LVL) glued with PF had higher strength than those glued with UF; and agrees with observations reported by Huang and Lin (1983) that particleboards glued with PF had higher MOE and MOR than those glued with UF. In general, bonding strength is affected by many factors, such as mole ratio and gelation time of adhesives, hot-pressing conditions, $\mathrm{pH}$ value and wettability of bamboo strips. Reasons accounting for the difference in bonding strength between PF and UF merit further study. 


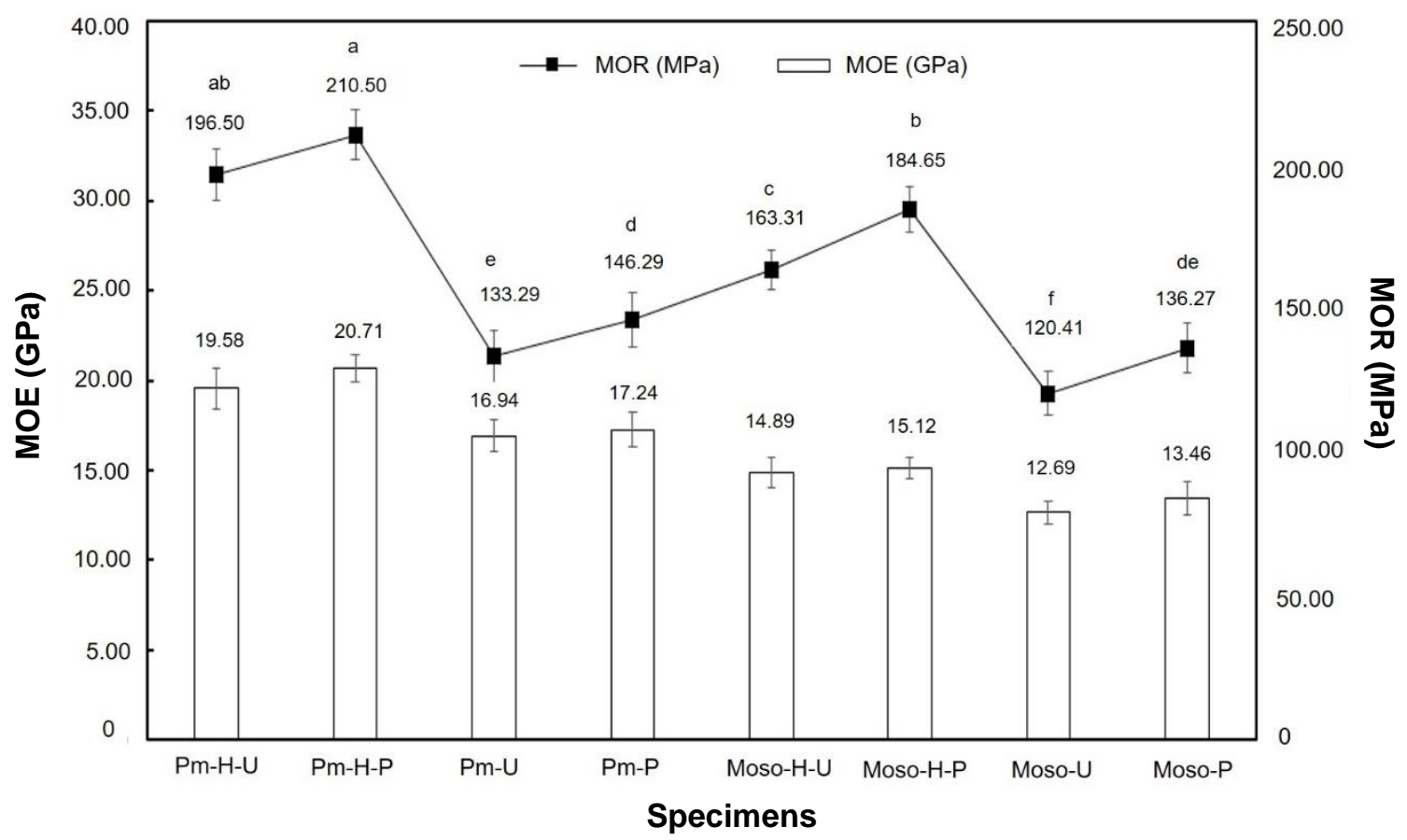

Fig. 2. $M O E(/ /)$ and $M O R(/ /)$ of eight experimental OBSB groups (results are mean $\pm \mathrm{SE}, \mathrm{n}=9$; numbers followed by different letters (a through $e$ ) are statistically different at a probability level of $p<0.05$ according to Tukey's test and ANOVA)

\section{Screw Holding Strength}

Figure 3 shows the SHS of the experimental OBSB groups. As can be seen, MosoOBSB specimens had higher SHS than their Pm-OBSB counterparts.

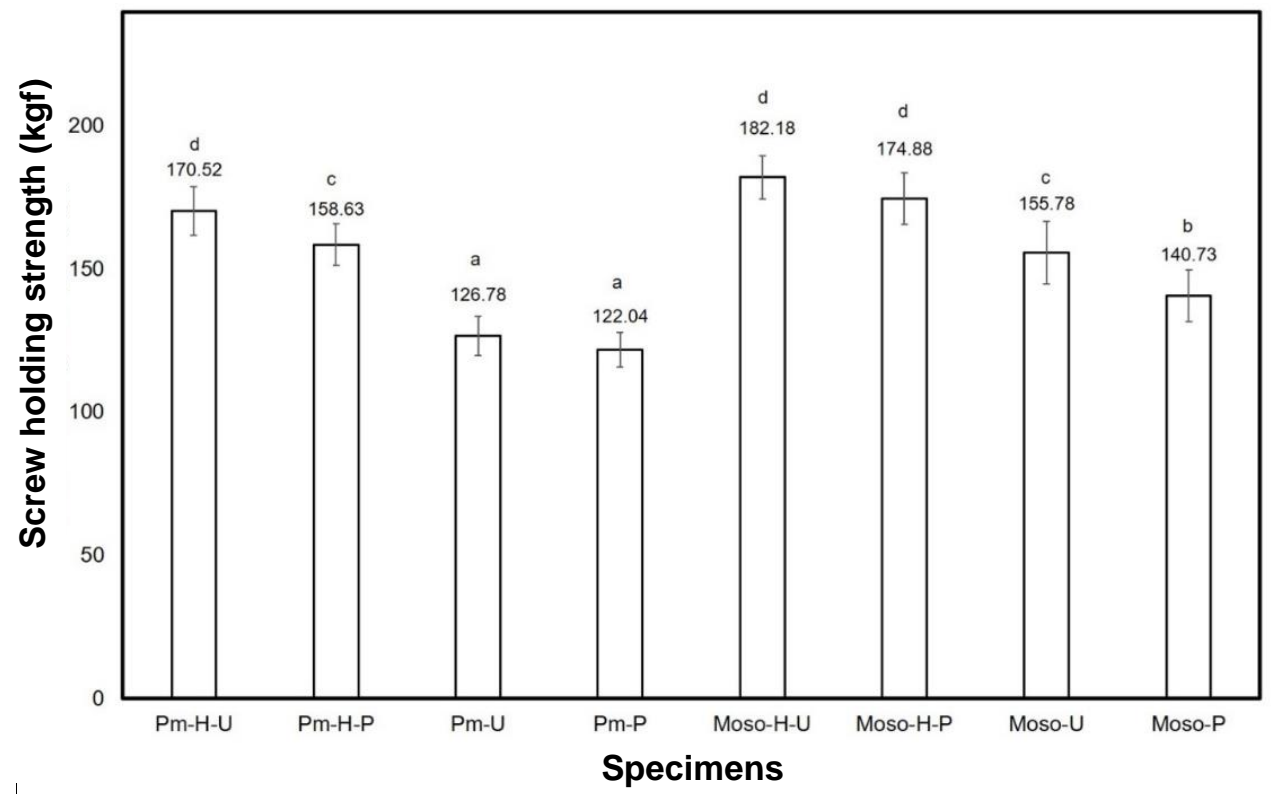

Fig. 3. Screw holding strength of eight experimental OBSB groups (results are mean $\pm S E, n=9$; numbers followed by different letters (a through $\mathrm{e}$ ) are statistically different at a probability level of $p<0.05$ according to Tukey's test and ANOVA) 
Regardless of bamboo species, heat-treated specimens had higher SHS than their non-treated counterparts, suggesting that SHT contributes to enhanced SHS. Moreover, UF-glued specimens, whether heat-treated or not, had higher SHS than their PF-glued counterparts, showing that SHS was improved when using UF as adhesive. Moso-H-U had the highest SHS of $182.18 \mathrm{kgf}$, and Pm-P had the lowest SHS of $122.04 \mathrm{kgf}$. These results showed that optimal SHS was obtained using heat-treated moso bamboo glued with UF, which is related to increased internal bond strength (IB) (Kojima and Suzuki 2011). Lin and Huang (2001) also reported higher SHS for hot-pressed particleboards with higher densification, stronger cohesion, and better gluing quality.

\section{Dimensional Stability}

Table 4 displays the results for WA\%, TS\%, and S\%, which are all indicators of dimensional stability. Higher WA\% was observed in Moso-OBSB than in Pm-OBSB. Moreover, regardless of bamboo species, non-heat-treated specimens had higher WA\% than their heated counterparts, indicating that SHT reduced water absorption. Furthermore, PF-glued specimens, whether heat-treated or not, had higher WA\% than their UF-glued counterparts. Hence, the highest WA\% (35.89\%) was observed in Moso-P, while the lowest WA\% (14.83\%) was found in Pm-H-U. As shown in Table 4, OBSB made from non-heattreated moso bamboo using PF as adhesive had higher TS\% and S\%. The highest TS\% (16.96\%) and S\% (26.41\%) were observed in Moso-P, while the lowest TS\% (6.99\%) and $\mathrm{S} \%(10.48 \%)$ were observed in Moso-H-U. These findings indicated reduction in thickness and volume expansion after SHT. Moreover, Table 4 also revealed that PF-glued OBSB had higher WA\%, TS\% and S\% than their UF-glued counterparts, indicating lower dimensional stability in PF-glued OBSB, which can be attributed to the lower permeability and wettability between bamboo strips and alcohol-based PF (molecular weight $=134.13$ $\mathrm{g} / \mathrm{mol}$ ) compared with water-based UF (molecular weight $=90.08 \mathrm{~g} / \mathrm{mol}$ ).

Table 4. Thickness Swelling, Volumetric Swelling, and Water Absorption of Eight Experimental OBSB Groups

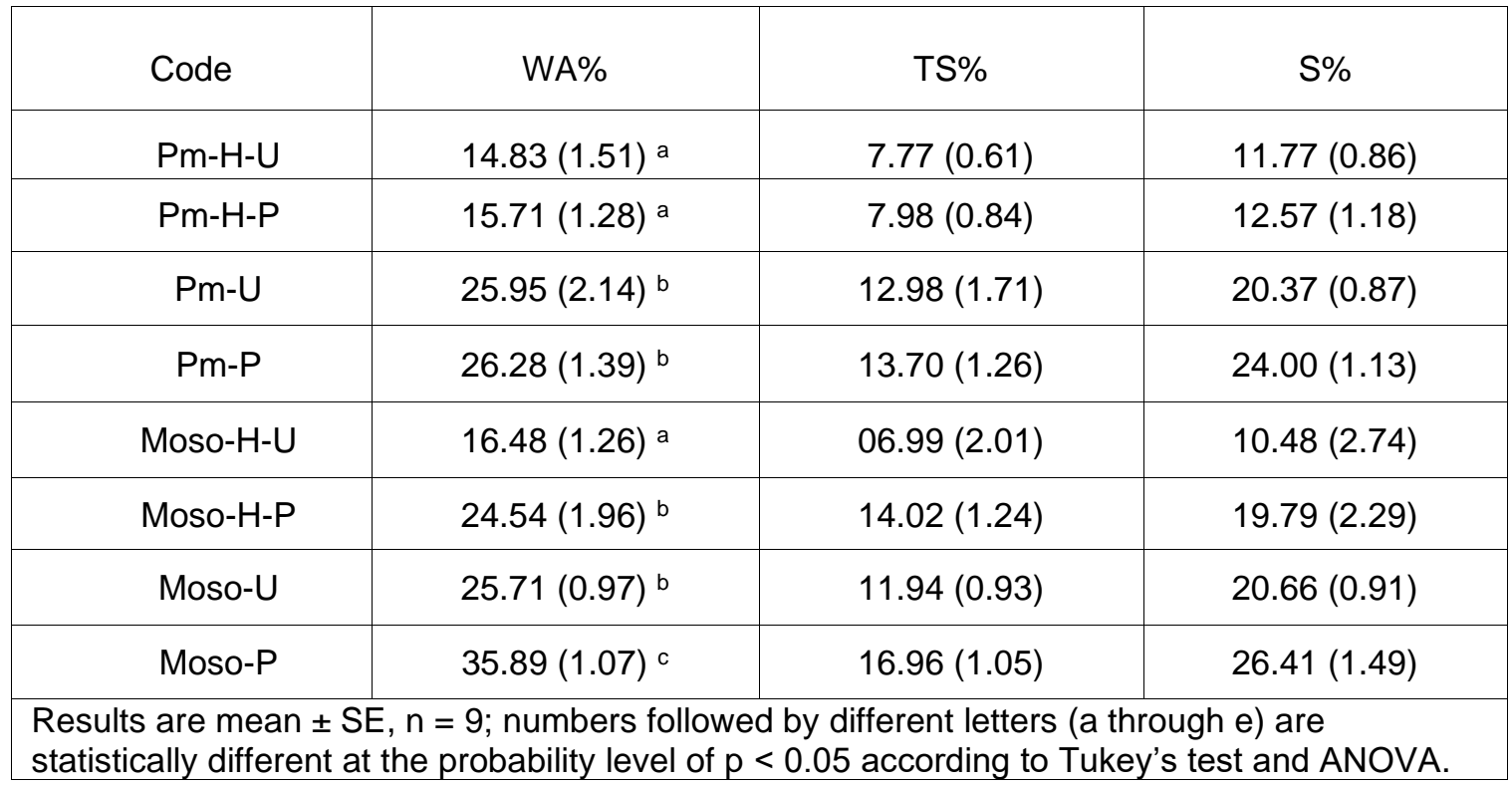


Lee et al. (1996) examined both physical and mechanical properties of moso bamboo-made strand board and found that the amount of adhesives used affected the MOE, MOR, and IB, but not the spring-back rate, linear expansion, or nail withdrawal resistance. Yu et al. (2015) found that water absorption of OBSB influenced the board structure and bond strength of fibers, which undermined the dimensional stability, mechanical properties, and physical properties of the entire product. Mohebby and Llbeighi (2007) reported degradation of woody material in hemicellulose with good hygroscopic properties during heat treatment. Such treatment also caused the non-crystalline region in cellulose to degrade and increased the crystallinity of the fiber, which prevented moisture from entering the fiber. Previous analysis also showed decreased equilibrium moisture content in heattreated bamboo. Therefore, heat treatment reduces the hygroscopicity of bamboo. This finding is consistent with the results reported by Huang et al. (1993) on the water absorption properties of moso bamboo after heat treatment with three different media.

\section{CONCLUSIONS}

1. The dry density of oriented bamboo scrimber board (OBSB) made with different bamboo species and adhesives was approximately $1.0 \mathrm{~g} / \mathrm{cm}^{3}$ with insignificant variation. In contrast, the percent moisture content (MC\%) of OBSB decreased after SH. MC\% was slightly lower in PF-glued OBSB than in UF-glued OBSB. PF-glued Pm-OBSB had significantly higher ultrasonic wave velocity $\left(V_{\mathrm{u}(/ /)}\right)$, tap tone sound velocity $\left(V_{\mathrm{t}(/ /)}\right)$, dynamic modulus of elasticity $\left(\mathrm{DMOE}_{\mathrm{u}(/ /)}\right)$, and $\mathrm{DMOE}_{\mathrm{t}(/)}$ than UFglued Moso OBSB ( $\mathrm{p}<0.05)$.

2. Regardless of bamboo species and adhesive used, and whether heat-treated or not, OBSBs had DMOE $\mathrm{DMOE}_{\mathrm{u}}>\mathrm{DMOE}_{\mathrm{t}}>\mathrm{Mechanical}$ strength of OBSB made from makino bamboo and glued with PF was larger than OBSB made from moso bamboo and glued with UF. Steam-heated Pm-OBSB glued with PF (Pm-H-P) showed the highest strength of $210.5 \mathrm{MPa}$, while steam-heated Moso-OBSB glued with UF (Moso$\mathrm{H}-\mathrm{U})$ had the highest SHS.

3. Heat treatment reduced WA\%, TS\%, and S\% of both Pm-OBSB and Moso-OBSB. Whether heat-treated or not, OBSB glued with UF had lower WA \%, TS\%, and S\% than that glued with PF.

\section{ACKNOWLEDGEMENTS}

The authors are grateful for the financial support from the Forestry Bureau, Taiwan, Republic of China, and the Experimental Forest, College of Bioresource and Agriculture, National Taiwan University, Taiwan, ROC under grant No. 109-C02. 


\section{REFERENCES CITED}

Abdul Khalil, H. P. S., Bhata, I. U. H., Jawaid, M., Zaidon, A., Hermawan, D., and Hadi, Y. S. (2012). "Bamboo fibre reinforced biocomposites: A review," Mater. Design 42, 353-368. DOI: 10.1016/j.matdes.2012.06.015

ASTM D1037 (2006). "Evaluating the properties of wood-based fiber and particleboard material," ASTM International, West Conshohocken, PA, USA.

Bal, B. C., and Bektaş, Í. (2012). "The effects of wood species, load direction, and adhesives on bending properties of laminated veneer lumber," BioResources 7(3), 3104-3112. DOI: 10.15376/biores.7.3.3104-3112

Chung, M.-J., and Wang, S.-Y. (2017). "Effects of peeling and steam-heating treatment on basic properties of two types of bamboo culms (Phyllostachys makinoi and Phyllostachys pubescens)," J. Wood Sci. 63(5), 473-482. DOI: 10.1007/s10086-0171647-y

Chung, M.-J., and Wang, S.-Y. (2018). "Mechanical properties of oriented bamboo scrimber boards made of Phyllostachys pubescens (moso bamboo) from Taiwan and China as a function of density," Holzforschung 72(2), 151-158. DOI: 10.1515/hf2017-0084

CNS 451 O2002 (2013). "Wood - Determination of density for physical and mechanical tests," Bureau of Standards, Metrology and Inspection, Taipei, Taiwan.

CNS 452 O2003 (2005). "Wood - Determination of moisture content for physical and mechanical tests," Bureau of Standards, Metrology and Inspection, Taipei, Taiwan.

CNS 2215 O1012 (2012). "Particleboards," Bureau of Standards, Metrology and Inspection, Taipei, Taiwan.

Çolak, S., Aydin, Í., Demirkir, C., and Çolakoglu, G. (2004). "Some technological properties of laminated veneer lumber manufactured from pine (Pinus sylvestris L.) veneers with melamine added-UF resins," Turk J. Agric. For. 28(2), 109-113.

Geng, Y., Li, K., and Simonsen, J. (2004). "Effects of a new compatibilizer system on the flexural properties of wood-polyethylene composites," J. Appl. Polym. Sci. 91(6), 3667-3672. DOI: 10.1002/app.13618

Hakkou, M., Pétrissans, M., Bakali, I., Gérardin, P., and Zoulalian, A. (2005). "Wettability changes and mass loss during heat treatment of wood," Holzforschung 59(1), 35-37. DOI: 10.1515/HF.2005.006

Halabe, U. B., Bidigalu, G. M., Gangarao, H. V. S., and Ross, R. J. (1997).

"Nondestructive evaluation of green wood using stress wave and transverse vibration techniques," Mater. Eval. 55(9), 1013-1018.

Huang, Y.-F., and Lin, C.-J. (1983). "Formosan, alder and wood oil tree as raw materials for particleboard manufacture," Forest Products Industries 2(2), 46-63. DOI: 10.6561/FPI.1983.2(2).4 (In Chinese)

Huang, Y.-S., Chen, S.-S., and Chi, S.-C. (1993). "Feasibility of the evaluation of log quality by using nondestructive test method," Taiwan Journal of Forest Science 3(1), 85-98. DOI: 10.7075/BTFRI.199303.0085 (In Chinese)

Kojima, Y., and Suzuki, S. (2011). "Evaluating the durability of wood-based panels using internal bond strength results from accelerated aging treatments," J. Wood Sci. 57(1), 7-13. DOI: $10.1007 / \mathrm{s} 10086-010-1131-4$ 
Lee, A. W. C., Bai, X., and Bangi, A. P. (1998). "Selected properties of laboratory-made laminated bamboo lumber," Holzforschung 52(2), 207-210. DOI: 10.1515/hfsg.1998.52.2.207

Lee, A. W. C., Bai, X., and Peralta, P. N. (1996). "Physical and mechanical properties of strandboard made from moso bamboo," Forest Prod. J. 46(11/12), 84-88.

Lee, A. W. C., and Liu, Y. (2003). "Selected physical properties of commercial bamboo flooring," Forest Prod. J. 53(6), 23-26.

Lee, C.-H., Chung, M.-J., Lin, C.-H., and Yang, T.-H. (2012). "Effects of layered structure on the physical and mechanical properties of laminated moso bamboo (Phyllostachys edulis) flooring," Constr. Build. Mater. 28(1), 31-35 DOI: 10.1016/j.conbuildmat.2011.08.038

Lee, C. J., and Yang, T. H. (2010). "Evaluation of bending properties of China fir laminae using nondestructive testing," Quarterly Journal of Forest Research 32(4), 45-60. DOI: 10.29898/SHBQ.201012.0005 (In Chinese)

Lin C.-J., Tsai, M.-J., and Wang, S.-Y. (2006). "Nondestructive evaluation techniques for assessing dynamic modulus of elasticity of moso bamboo (Phyllostachys edulis) lamina," J. Wood Sci. 52(4), 342-347. DOI: 10.1007/s10086-005-0772-1

Lin, H. C., and Huang, J. C (2001). "Apply fade effective image processing analysis technique to evaluate internal bond strength of particle board," Quarterly Journal of Forest Research 23(2), 13-24. (In Chinese)

Liu, C. T. (1984). "Types and properties of adhesives for wood products," Forest Products Industries 3(1), 92-98. DOI: 10.6561/FPI.1984.3(1).7 (In Chinese)

Liu, C. T., Lee, W. J., and Wang, Y. H. (1993). "Laminated bamboo for high value-added products-the properties of adhesives used in laminated bamboo and the development of their bonding strength," Forest Products Industries 12(3), 51-64. DOI: 10.6561/FPI.1993.12(3).4 (In Chinese)

Mohebby, B., and Llbeighi, F. (2007). "Physical and mechanical properties of hydrothermally modified medium density fiberboard (MDF)," in: Proceedings of the International Panel Products Symposium, Cardiff, Wales, pp. 341-348.

Nugroho, N., and Ando, N. (2001). "Development of structural composite products made from bamboo II: Fundamental properties of laminated bamboo lumber," J. Wood Sci. 47(3), 237-242. DOI: 10.1007/BF01171228

Obata, Y., Takeuchi, K., Soma, N., and Kanayama, K. (2006). "Recycling of wood waste as sustainable industrial resources - Design of energy saving wood-based board for floor heating systems," Energy 31(13), 2341-2349. DOI:

10.1016/j.energy.2006.02.001

Okubo, K., Fujii, T., and Yamamoto, Y. (2004). "Development of bamboo-based polymer composites and their mechanical properties," Compos. Part A-Appl. S. 35(3), 377-383. DOI: 10.1016/j.compositesa.2003.09.017

Pizzi, A. (1993). Wood Adhesives: Chemistry and Technology Volume 1, Marcel Dekker, Monticello, NY, USA.

Sharma, B., Gatóo, M. B., and Ramage, M. (2015a). "Engineered bamboo for structural applications," Constr. Build. Mater. 81(15), 66-73. DOI: 10.1016/j.conbuildmat.2015.01.077

Sharma, B., Gatóo, A., and Ramage, M. H. (2015b). "Effect of processing methods on the mechanical properties of engineered bamboo," Constr. Build. Mater. 83(15), 95-101. DOI: 10.1016/j.conbuildmat.2015.02.048 
Sulastiningsih, I., and Nurwati, M. (2009). "Physical and mechanical properties of laminated bamboo board," J. Trop. For. Sci. 21(3), 246-251.

Tsai, Z. F. (1985). Wood Mechanical Properties, Xushi Culture and Education Foundation, Taipei, Taiwan.

Uysal, B. (2005). "Bonding strength and dimensional stability of laminated veneer lumbers manufactured by using different adhesives after the steam test," Int. J. Adhes. Adhes. 25(5), 395-403. DOI: 10.1016/j.ijadhadh.2004.11.005

Verma, C. S., and Chariar, V. M. (2012). "Development of layered laminate bamboo composite and their mechanical properties," Compos. Part B-Eng. 43(3), 1063-1069. DOI: 10.1016/j.compositesb.2011.11.065

Wang, J. X. (1989). "Bamboo scrimber: Novel technology and novel product," China Wood Industry 3(4), 52-53. (In Chinese)

Wang, S.-Y., Chen, J.-H., Tsai, M.-J., Lin, C.-J., and Yang, T.-H. (2008). "Grading of softwood lumber using non-destructive techniques," J. Mater. Process. Tech. 208(13), 149-158. DOI: 10.1016/j.jmatprotec.2007.12.105

$\mathrm{Yu}, \mathrm{W} .-\mathrm{J}$. , and Yu, Y.-L. (2013). "Development and prospect of wood and bamboo scrimber industry in China," China Wood Industry 27(1), 5-8. DOI: 10.19455/j.mcgy.2013.01.001 (In Chinese)

Yu, Y., Zhu, R., Wu, B., Hu, Y., and Yu, W. (2015). "Fabrication, material properties, and application of bamboo scrimber," Wood Sci. Technol. 49, 83-98. DOI: 10.1007/s00226-014-0683-7

Article submitted: February 10, 2020; Peer review completed: March 28, 2020; Revised version received and accepted: April 19, 2020; Published: May 21, 2020.

DOI: $10.15376 /$ biores.15.3.5342-5354 